\title{
Beyond clinical outcomes: the social and healthcare system implications of hepatitis C treatment
}

\author{
Marta Torrens ${ }^{1,2^{*}}$ (D, Tokunbo Soyemi ${ }^{3}$, Darcy Bowman ${ }^{4}$ and Eberhard Schatz ${ }^{5}$
}

\begin{abstract}
Background: Hepatitis C virus (HCV) infections in people who inject drugs (PWID) can now be treated and cured. However, the impact that HCV treatment has on drug-user health, practices and wellbeing is not known. The aim of this research was to understand the non-clinical impact that HCV treatment has in PWID and their reasons for accessing and completing treatment.

Methods: Participants aged 25-67 years who had injected opioids or stimulants (currently or in the past) and had completed direct-acting antiviral treatment were recruited from seven European countries. Participants completed a 30-min online survey administered face-to-face between September 2018 and April 2019. The questionnaire responses were used to assess the mental and physical impact of having completed treatment.

Results: Of the 124 participants who completed the survey questionnaire, 75\% were male, 69\% were over 45 years old and $65 \%$ were using opioids and/or stimulants at the start of HCV treatment. Participants reported improvements in the following areas after completing HCV treatment: outlook for the future (79\%); self-esteem (73\%); ability to plan for the future (69\%); belief in their abilities (68\%); confidence (67\%); empowerment (62\%); energy levels (59\%); and ability to look after themselves (58\%). The most common reasons for starting HCV treatment were: becoming aware of treatments that were well tolerated (77\%) and effective (75\%); and understanding the potentially severe consequences of HCV (75\%).

Conclusions: The benefits of HCV treatment go beyond clinical outcomes and are linked to improved drug-user health and wellbeing. Sharing information about well-tolerated and effective HCV treatments, and raising awareness about the potentially severe consequences of untreated HCV are likely to increase the number of PWID who are motivated to access and complete HCV treatment in future.
\end{abstract}

Keywords: Hepatitis C, Outcomes, Experience, People who inject drugs, Mental health, Physical wellbeing

\footnotetext{
*Correspondence: MTorrens@parcdesalutmar.cat

${ }^{1}$ Addiction Research Group, Hospital del Mar Medical Research Institute, Barcelona, Spain

${ }^{2}$ Department of Psychiatry and Forensic Medicine, Universitat Autònoma de Barcelona, Barcelona, Spain

Full list of author information is available at the end of the article
}

(c) The Author(s). 2020 Open Access This article is licensed under a Creative Commons Attribution 4.0 International License, which permits use, sharing, adaptation, distribution and reproduction in any medium or format, as long as you give appropriate credit to the original author(s) and the source, provide a link to the Creative Commons licence, and indicate if changes were made. The images or other third party material in this article are included in the article's Creative Commons licence, unless indicated otherwise in a credit line to the material. If material is not included in the article's Creative Commons licence and your intended use is not permitted by statutory regulation or exceeds the permitted use, you will need to obtain permission directly from the copyright holder. To view a copy of this licence, visit http://creativecommons.org/licenses/by/4.0/ The Creative Commons Public Domain Dedication waiver (http://creativecommons.org/publicdomain/zero/1.0/) applies to the data made available in this article, unless otherwise stated in a credit line to the data. 


\section{Background}

Chronic hepatitis $\mathrm{C}$ is an important public health problem, with an estimated 71 million people living with the hepatitis $\mathrm{C}$ virus (HCV) across the globe in 2015 [1]. If left untreated, hepatitis $\mathrm{C}$ can progress to serious liver disease; the estimated probability of cirrhosis at 20 years after $\mathrm{HCV}$ infection is $16 \%$ [2].

The recent introduction of simple, highly effective and well-tolerated direct-acting antiviral (DAA) treatment regimens for $\mathrm{HCV}$ provides an opportunity to reduce prevalence and ultimately eliminate $\mathrm{HCV}$ infection as a public health threat [3]. For example, significant progress towards HCV elimination has been made in Iceland, with $81 \%(603 / 741)$ of people identified as HCV-positive cured through a 3-year national elimination programme [4]. To achieve $\mathrm{HCV}$ elimination, treatment of populations at high risk of infection such as people who inject drugs (PWID), should be prioritised [5]. In Europe, HCV prevalence among people with recent injection drug use is between 39.9 and $48.6 \%$ whereas $\mathrm{HCV}$ prevalence in the general population is approximately $1.5 \%[1,6]$. In fact, injection drug use is the main driver of $\mathrm{HCV}$ infection in Europe, with approximately $80 \%$ of new cases attributable to this high-risk behaviour [7]. Although DAA therapy can cure the majority of people living with $\mathrm{HCV}$, there are still some physical and psychological barriers that prevent people, including PWID, from accessing HCV care and treatment $[8,9]$. The psychological impact of living with hepatitis $C$ is well-documented with many people experiencing depression and anxiety $[10,11]$. These symptoms, which are very common among PWID, may affect people's willingness to initiate HCV treatment $[12,13]$.

There is a gap in knowledge on the factors that encourage PWID to start DAA treatment and on the impact treatment has on drug-user health, practices and wellbeing. Therefore, the aim of this investigation was to survey injection drug users who have received DAA treatment in order to gain insights on the non-clinical impact that HCV treatment has had on their life, and on wider society. Additionally, the study aimed to ascertain the main reasons these participants were motivated to access and complete HCV treatment, as well as survey the participants' opinions on the factors that may encourage more PWID to engage in $\mathrm{HCV}$ care.

\section{Methods}

\section{Study population}

Participants included in this study were aged between 25 and 67 years, were either injecting opioids or stimulants regularly (at least once a week), injecting occasionally (less than once a week) or had previously injected opioids or stimulants. The participants had also received a confirmed diagnosis of hepatitis C (self-reported) and completed DAA treatment. Participants were incentivised to take part in the study in the form of vouchers. Each participant was offered physical or digital vouchers (supermarket or Amazon) worth 50 euros ( $£ 50$ in the UK).

\section{Recruitment}

The aim was to recruit eight injection drug users per country in the UK (Brighton and Blackpool), France (Montpellier and Marseille), Germany (Essen and Cologne), Italy (Rome) and Spain (Bilbao), and six injection drug users per country in Portugal (Lisbon and Porto) and Switzerland (Lugano). Recruitment channels in these countries included patient associations/organisations, referrals from healthcare professionals (HCPs), recruiter panels (local databases of patients and HCPs from a variety of specialties), patient referrals and online campaigns. Invitations to participate in the survey were sent via these channels in September 2018. A team of local fieldwork partners/recruiters with experience in healthcare market research conducted recruitment in each of the countries. Physicians (from the recruiter panels) and patient associations/organisations were contacted by email or telephone to invite them to assist with patient referrals. In this communication, they were provided with a letter detailing information about the study, invited to help refer suitable patients and given details of the referral incentive. The incentive consisted of donations ranging from 100 to 1000 euros or $£ 100-£ 1000$ in the UK (depending on how many participants were referred) to charities and addiction centres for their support in referring participants. Physical or digital vouchers (supermarket or Amazon) worth 50 euros ( $£ 50$ in the UK) were offered to participants who referred other participants to the survey. In Portugal, there were no incentives given for referrals due to country regulations. No healthcare professionals were paid any referral incentives. Physicians were invited to tell patients about the study and provide them with the recruiter's contact details. Patients were free to contact the recruiter if they were interested in participating. The recruiters also advertised the study and provided information about how to take part via various channels including the recruiter panel website, social media and patient association forums, newsletters and websites.

\section{Survey}

The survey questionnaire was developed by Incite, an independent international market research consultancy (Supplementary File 1). The authors, who have a wide knowledge of hepatology and addiction, contributed to the development of the questionnaire and decisions on which outcomes to measure. They reviewed the final version to ensure alignment with the research objectives and that the questions were appropriate for participants. The survey comprised of 25 questions relating to participants' sociodemographic characteristics, injecting behaviours and HCV treatment. The survey also included 
seven questions on the perceived impact of HCV treatment on different aspects of the participants' lives. The survey was hosted online on the Confirmit platform.

Once participants had agreed to participate, the online survey was conducted in-person (as a face-to-face interview) in the native language at a convenient location (e.g. a café, HCV nurse's office, rehabilitation centre, drug addiction clinic or patient's home). The interviews were carried out by moderators (non-HCPs) with experience working in healthcare market research, including patient research. All moderators had received training on how to ask questions on topics of a sensitive nature. At the beginning of every interview, participants were reassured on the anonymity of their responses to encourage open and honest feedback. All responses provided by the participant were inputted onto a tablet or laptop by the moderator. Data were collected on the Confirmit platform. Incite researchers and analysts collated and analysed the data using Q Research Software.

\section{Data collection}

The surveys were carried out from 13 September 2018 to 11 April 2019 and took $30 \mathrm{~min}$ to complete on average.

\section{Results}

\section{Baseline characteristics of participants}

In this study, 124 participants completed the survey questionnaire. The target for the minimum number of participants per country was met with 100 respondents from the UK, Germany, France, Italy and Spain (20 per country), 15 from Portugal and 9 from Switzerland. Of the 124 participants who completed the survey, the majority $(75 \%)$ were male and aged over 44 years old (69\%). Many received a confirmed HCV diagnosis before 2008 (73\%) and concurrent illnesses were common (Table 1). Overall, $65 \%$ of participants were using opioids and/or stimulants at the start of HCV treatment, and the other $35 \%$ had a history of injection drug use. Most participants were recruited through a patient association/organisation $(62 \%)$ or through a referral from an $\mathrm{HCP}$ (20\%). The majority (78\%) received treatment less than 3 years ago and treatment was most often received from a secondary care hospital (73\%).

Self-perceived impact of HCV treatment on mental health and physical wellbeing

Participants reported on the impact (significant positive, some positive, some negative, significant negative or none) of HCV treatment on various mental and emotional treatment-related outcomes (Fig. 1a). A positive impact (defined as either a significant positive impact or some positive impact) with HCV treatment was reported by a high proportion of participants on the following outcomes: outlook for the future (79\%); self-esteem (73\%); ability to plan for the future (69\%); belief in their abilities (68\%); and confidence (67\%). A small number of participants reported a negative impact (defined as either some negative impact or significant negative impact) on psychological health (3\%) and their ability to be open with others (1\%). For all mental health-related outcomes except psychological/mental health, the percentage of people who reported a positive impact with $\mathrm{HCV}$ treatment was higher in participants who no longer used opioids/stimulants at the time of the survey compared with those who did (Fig. 1b).

For physical health, a positive impact on energy levels and fatigue/tiredness with HCV treatment was reported in 59 and $53 \%$ of participants, respectively (Fig. 1a). Few participants reported a negative impact on their physical wellbeing, with the most common negative outcomes being tiredness/fatigue (6\%) or inability to maintain a healthy weight (6\%). Additionally, most participants (82\%) reported that HCV treatment had no impact on pain. Among participants who used opioids/stimulants at the start of therapy, the parameter with the greatest numerical difference between participants who no longer used opioids/stimulants at the time of the survey and those who did was the ability to maintain a healthy weight (44\% compared with 30\%) (Fig. 1b).

\section{Self-perceived impact of HCV treatment on lifestyle, ability to engage in wider society and ability to maintain personal relationships}

Over half $(58 \%)$ of participants reported a positive impact in their ability to look after themselves and just under half $(47 \%)$ reported a positive impact on their ability to fulfil daily commitments to others (Fig. 2). Overall, 46\% reported a positive impact on their ability to enjoy/explore new interests and hobbies with many participants starting new activities after completing treatment: $6 \%$ started a sport or hobby; $13 \%$ obtained a new job; $19 \%$ enrolled in an education or training course; and $30 \%$ became an advocate regarding $\mathrm{HCV}$ and/or drug use (e.g. advising patients, companies or healthcare professionals) (Supplementary Fig. 1). For the parameters related to maintaining personal relationships, $35-41 \%$ of participants reported a positive impact with $\mathrm{HCV}$ treatment; the majority reported no impact.

\section{Accommodation and employment status before $\mathrm{HCV}$ treatment and during survey}

There were few changes to the participants' accommodation before and after $\mathrm{HCV}$ treatment: living in their own home from 36 to $44 \%$, respectively; in a family home from 22 to 25\%; in shared accommodation from 18 to $13 \%$; in a halfway house from 10 to $9 \%$; homeless 
Table 1 Baseline characteristics of survey participants $(N=124)$

\begin{tabular}{l} 
Characteristics \\
\hline Age, years \\
$18-29$ \\
$30-44$ \\
$45-60$ \\
$>60$ \\
Sex \\
Male \\
Female \\
Year HCV diagnosis was received \\
Before 1999 \\
1999-2003 \\
2004-2008 \\
2009-2013 \\
2014-2018
\end{tabular}

Comorbidities (more than one could be selected)

HBV
HIV
Cardiovascular disease
Diabetes
Other
Currently injecting drugs
$\geq$ once a week
$<$ once a week
No longer injecting

Use of opioids/stimulants at start of HCV treatment

Users

Non-users

Did not remember

Substances used

Opioids (e.g. heroin, morphine)

Stimulants (e.g. cocaine, amphetatmine)

Both opioids and stimulants

Other substances

$\%$

64

5

75

25

40

18

66

65

65

Country

UK

Germany

France

Italy

Spain

Portugal

Switzerland

Recruitment channel

Patient association/organisation

HCP referral
Table 1 Baseline characteristics of survey participants $(N=124)$ (Continued)

\begin{tabular}{ll}
\hline Characteristics & $\%$ \\
\hline Recruiter panel & 13 \\
Patient referral & 3 \\
Online campaign & 2 \\
Year started most recent HCV treatment & \\
$\geq 5$ years ago & 8 \\
4 years ago & 5 \\
3 years ago & 10 \\
2 years ago & 19 \\
1 year ago & 33 \\
This year & 26 \\
Where most recent HCV treatment was received & \\
Secondary care/hospital & 73 \\
Addiction clinic & 14 \\
GP/PCP & 5 \\
Prison & 2 \\
Other & 3
\end{tabular}

HCV treatment most recently received ${ }^{a}$ (more than one could be selected)

27

LDV/SOF

23

SOF

14

GLE/PIB

6

DCV

5

EBR/GZR 2

TEL

SOFNELNOX

$\mathrm{OBV} / \mathrm{PTV} / \mathrm{r}$

DSV 2

$\mathrm{BOC} 2$

Other/unknown 23

${ }^{2}$ The treatment regimen received by participants was at the discretion of their treating physician and was a function of the timing of the research, and/or regulatory approvals and reimbursement in each country $B O C$ Boceprevir, DCV Daclatasvir, DSV Dasabuvir, EBR Elbasvir, GLE Glecaprevir, GP General practitioner, GZR Grazoprevir, HBV Hepatitis B virus, HCP Healthcare professional, HCV Hepatitis C virus, HIV Human immodeficiency virus, LDV Ledipasvir, OBV Ombitasvir, PCP Primary care physician, PIB Pibrentasvir, PTV Paritaprevir, $r$ Ritonavir, SOF Sofosbuvir, TEL Telaprevir, VEL Velpatasvir, VOX Voxilaprevir

from 5 to $2 \%$; rehabilitation/detox centre from 5 to $4 \%$; and in prison from 2 to $0 \%$ (Supplementary Fig. 2). Employment status remained largely the same before and after completing HCV treatment: on benefits from 35 to $31 \%$, respectively; out of work from 44 to $41 \%$; employed (full- or part-time) from 24 to $23 \%$; retired from 8 to $7 \%$; and volunteer/peer work from 6 to 5\% (Supplementary Fig. 3). 


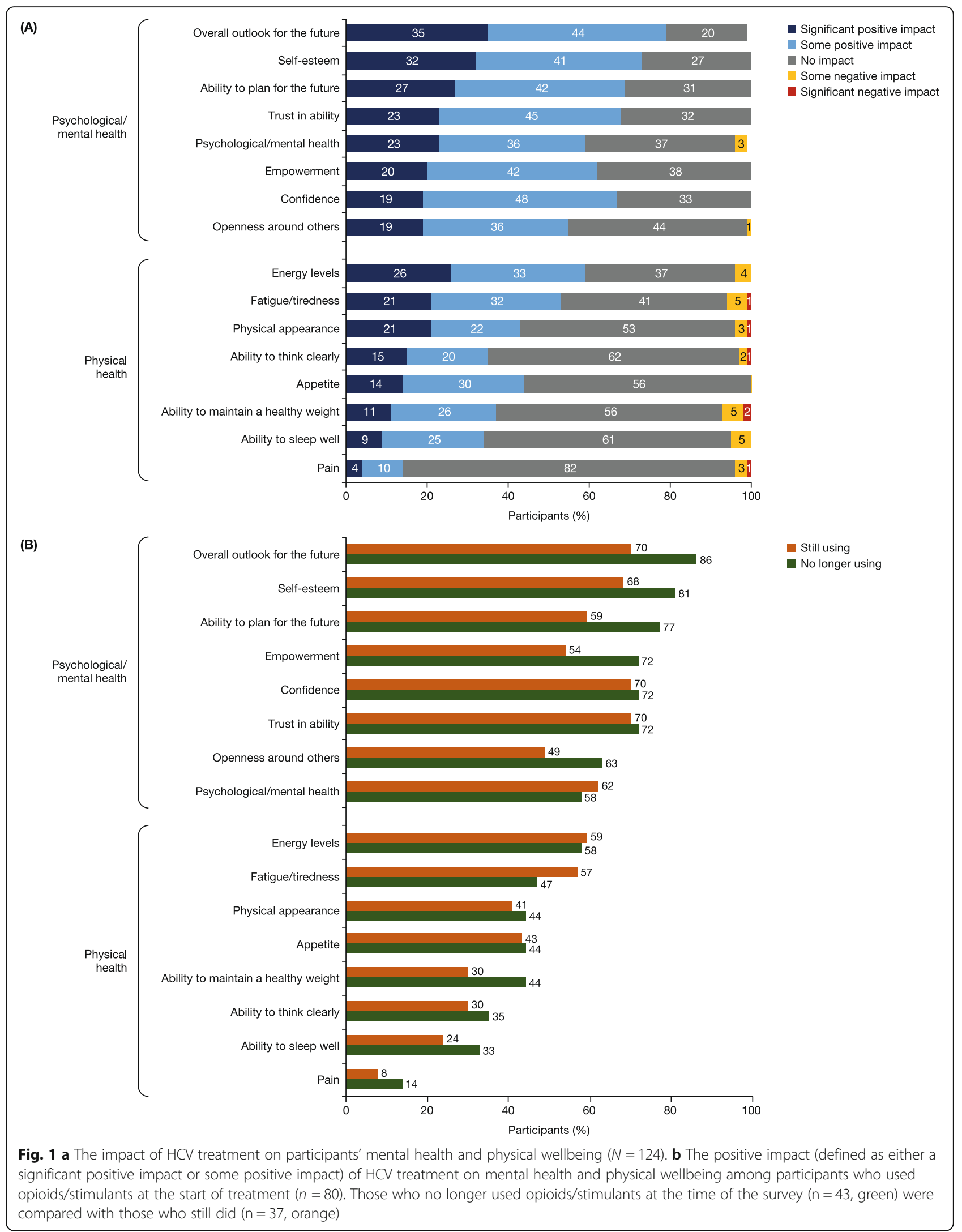




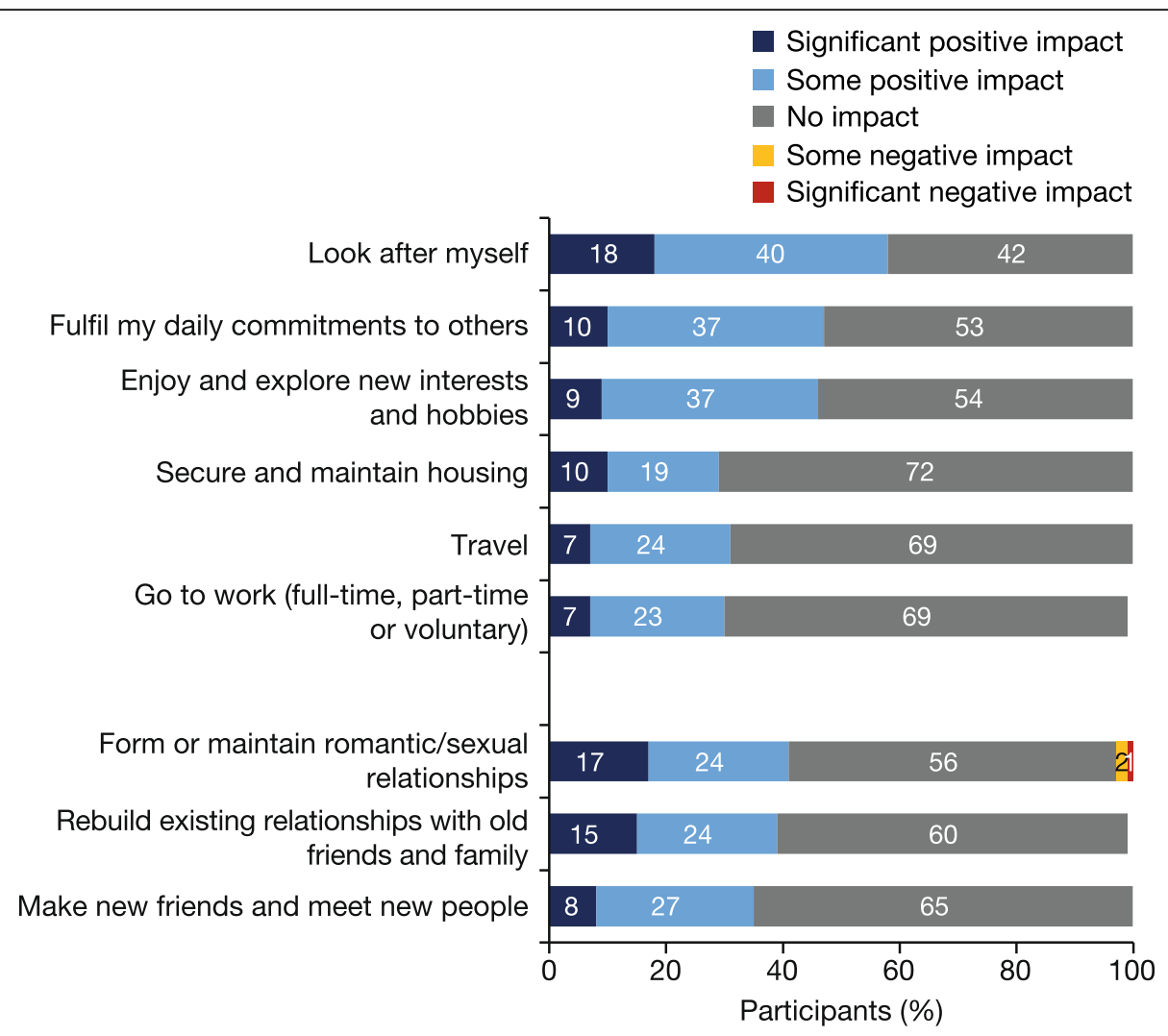

Fig. 2 The impact of HCV treatment on the ability of participants to maintain personal relationships and aspects of their lifestyle $(N=124)$

\section{Self-reported emotions felt after completing treatment}

The most common emotions reported by participants after completing treatment were: happy (73\%), relieved (71\%), optimistic (53\%); and proud (53\%) (Fig. 3a). Among participants who used opioids/stimulants at the start of therapy, the most common emotions felt after treatment were: relieved $(70 \%$ in participants who no longer used drugs at the time of the survey, $68 \%$ in users at the time of survey) and happy (67\% in non-users, $65 \%$ in users) (Fig. 3b). The emotions with the greatest numerical difference between participants who no longer used opioids/stimulants at the time of the survey and those who did were: successful (42\% in non-users, 19\% in users), free (53\% in non-users, $24 \%$ in users) and optimistic (60\% in non-users, $38 \%$ in users).

\section{Motivations for starting HCV therapy}

During the survey, 84 participants reported that someone else encouraged them to start treatment. Of those 84 participants: $75 \%$ were encouraged by an HCP; $21 \%$ by a family member; $19 \%$ by a social worker; $18 \%$ by a friend; $17 \%$ by an advocate or key worker; $12 \%$ by their partner; and $11 \%$ by one of their peers (Fig. 4).

The majority of participants $(\geq 75 \%)$ stated that becoming aware of treatments that were effective and well tolerated, as well as understanding the potentially severe consequences of $\mathrm{HCV}$, were their main reasons for starting therapy (Fig. 5a). Only 35\% of individuals identified that suffering symptoms of $\mathrm{HCV}$ was a motivation to start treatment. In the sub-population of individuals not using opioids/stimulants at the start of $\mathrm{HCV}$ treatment, $71 \%$ were concerned about the long-term consequences of the disease (Fig. 5b). For those who were drug users at the start of HCV treatment, the most frequently reported reason to start therapy was 'to get rid of the virus'. The participants agreed that raising awareness of effective and well-tolerated treatments (98\%), raising awareness about the risk and severity of $\mathrm{HCV}(96 \%)$, hearing about the positive experiences of others (94\%) and having a supportive $\mathrm{HCP}(93 \%)$ were the factors that were most likely to encourage others to start and complete HCV treatment (Fig. 6). The factor that was the least likely to encourage others was financial payments/incentives (41\%).

\section{Discussion}

This survey analysis shows that there are additional benefits to HCV treatment in PWID other than cure; many participants experienced a positive impact on other outcomes, mainly in their subjective psychological/mental health. These results align with previous studies which demonstrate that $\mathrm{HCV}$ treatment 

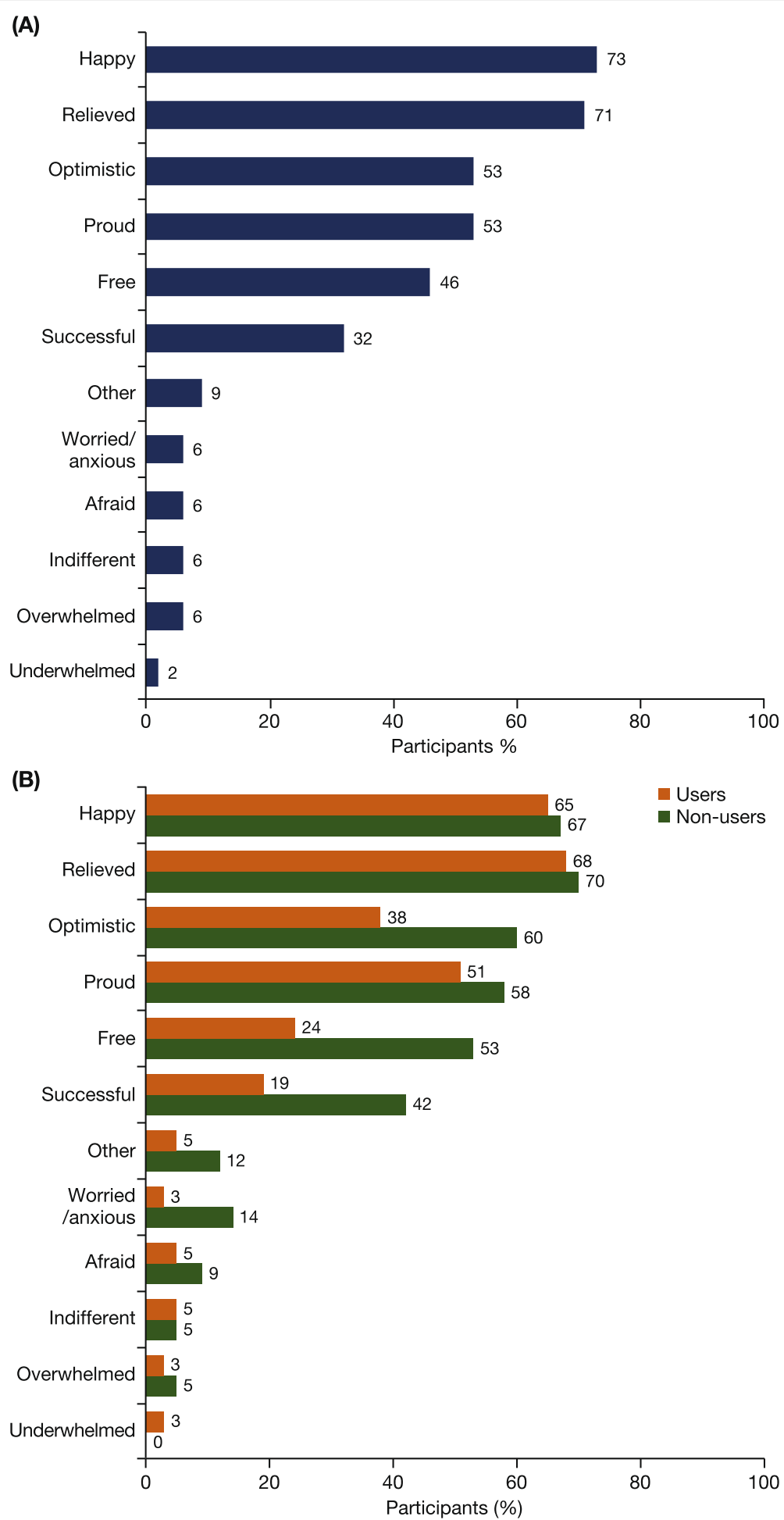

Fig. 3 a Emotions felt by participants after completing HCV treatment $(N=124)$. Participants were able to select more than one emotion. $\mathbf{b}$ Emotions felt by participants who used opioids/stimulants at the start of treatment $(n=80)$. Those who no longer used opioids/stimulants at the time of the survey ( $n=43$, green) were compared with those who still did ( $n=37$, orange) 


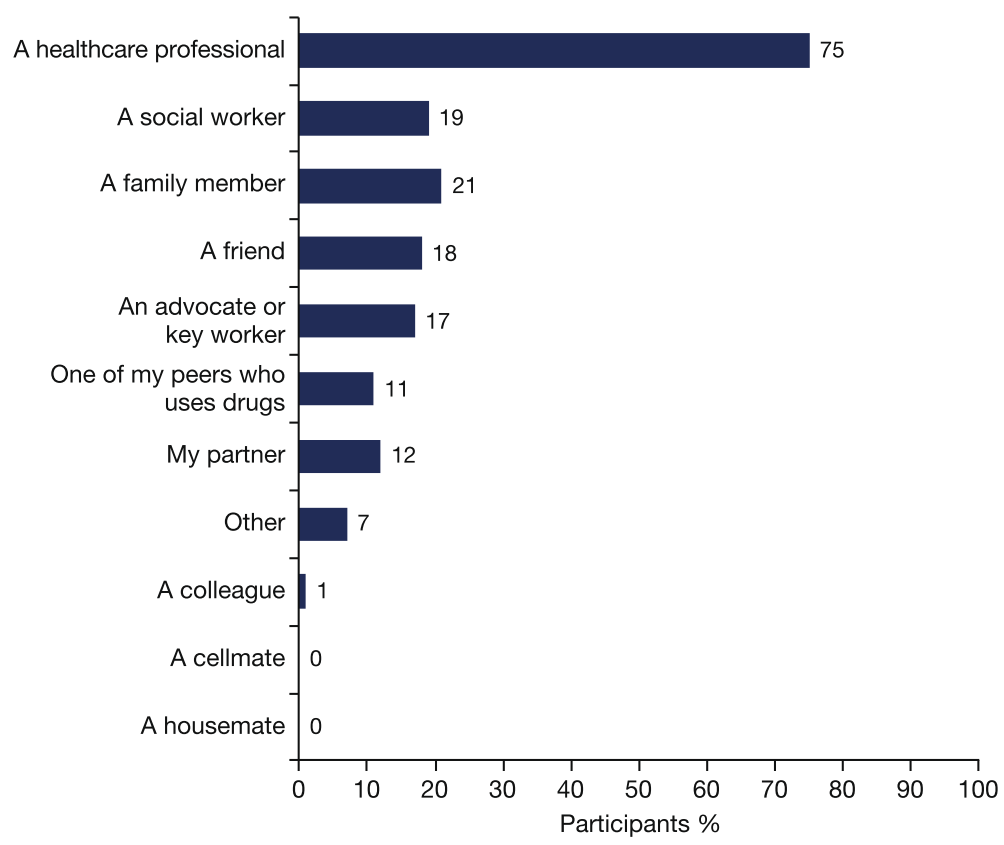

Fig. 4 The person who encouraged each participant to start HCV treatment $(N=84)$. Participants were able to select more than one person

has a transformative effect on patients' quality of life and mental wellbeing [14-17].

Despite these benefits, global $\mathrm{HCV}$ treatment uptake among PWID is low $[18,19]$. There are many systemlevel and provider-level reasons for this low treatment uptake but at an individual level, lack of awareness of $\mathrm{HCV}$ diagnosis, previous negative experiences with healthcare systems, stigma and physical/psychological co-morbidities have been identified as common barriers for PWID [20-22]. Another key barrier is lack of knowledge or misinformation about $\mathrm{HCV}$ and how it is treated [20]. Until 2013, the only treatments that were available for HCV were interferon (IFN)-based and required weekly injections for up to 1 year [23]. These IFN-based regimens were associated with many side effects and low efficacy rates, particularly among PWID $[24,25]$. Negative experiences of these poorly tolerated regimens have been shared among drug user communities which has resulted in many people being fearful of treatment side effects [26, 27].

With the advent of well-tolerated and orally administered DAA drugs, $\mathrm{HCV}$ treatment has become simpler and the majority of infected individuals, including PWID, can be treated and cured [28]. There is now consensus among the medical community that all patients should be able to access care and that treating PWID in particular is a priority to reduce $\mathrm{HCV}$ transmission [5, 29]. Pangenotypic regimens that are currently available require minimal pre-, during and post-treatment monitoring and can be used effectively to treat large numbers of previously underserved populations, thus maximising efforts towards HCV elimination [30].

There is still a need to understand what motivates PWID to engage in care. Qualitative research has illustrated that eliminating the virus is not the only factor that motivates PWID to start therapy [31]. The results of our survey suggest that awareness of the availability of effective and well-tolerated treatments and the potentially severe consequences of untreated $\mathrm{HCV}$ are key motivators. This highlights the importance of developing programmes and initiatives that include patient education to ensure that more PWID are treated for HCV [32]. In the Netherlands, education and awareness campaigns targeted at PWID have already been proven to be successful at engaging more individuals into care, with 257 additional PWID diagnosed with chronic HCV when these interventions were used compared to the control group [33]. An interesting topic for further research would be to survey PWID who decline HCV treatment to understand which factors influence their decision making.

Even in the era of simple DAA treatments that are effective in many patient populations, management of $\mathrm{HCV}$ among PWID is often perceived as challenging because this population is usually stigmatised by society and can find healthcare services difficult to access $[21,22,34]$. However, findings from this survey suggest that the majority of PWID reported a positive impact on their ability to engage in wider society and explore new interests/hobbies after $\mathrm{HCV}$ treatment. 


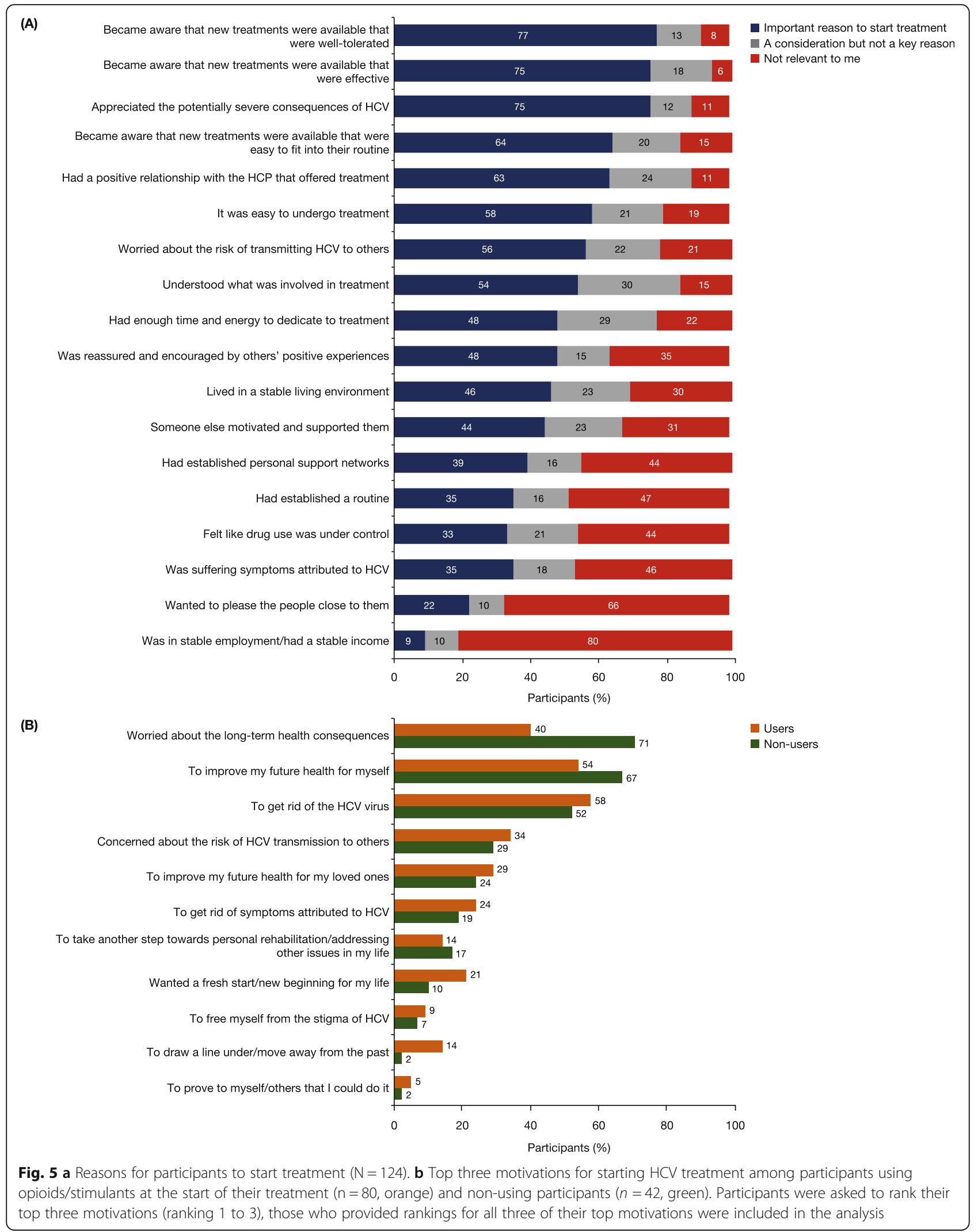




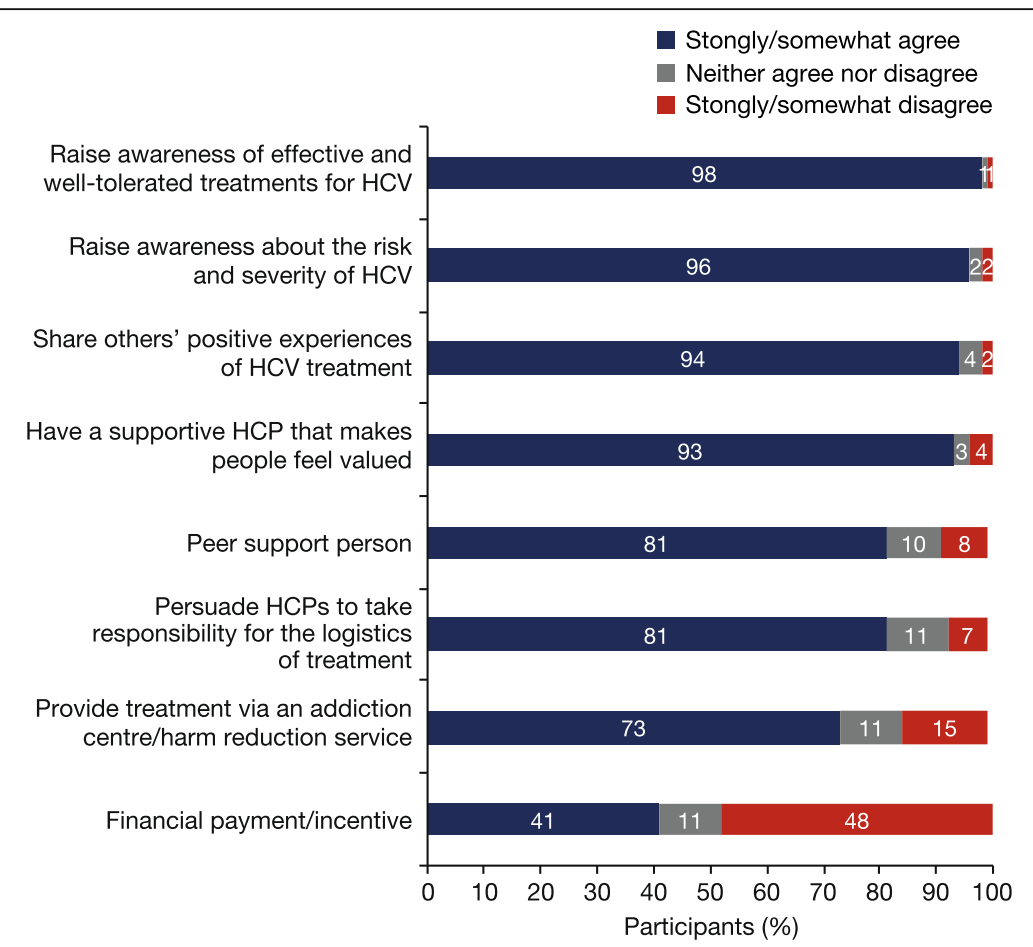

Fig. 6 Potential initiatives that participants agreed would help other PWID to start and complete HCV treatment $(N=124)$

Previous studies have also shown similar positive outcomes beyond $\mathrm{HCV}$ cure that are valued highly among PWID [16, 31].

In this analysis, there was wide variation in injecting patterns between participants, with different numbers of participants injecting drugs before and after $\mathrm{HCV}$ treatment. This highlights the complexity of this patient population and should be considered when interpreting the results. For example, for some outcomes such as overall outlook for the future, ability to plan for the future and empowerment, there was a large difference in the number of participants who reported a positive impact with $\mathrm{HCV}$ treatment between those who used drugs at the time of the survey and those who did not. It is not clear why this is the case however it suggests that injection drug use could also have an impact on these outcomes. Previous research has demonstrated that stopping drug use can improve an individual's mental and physical health, and therefore their quality of life $[35,36]$.

The results of this research should be interpreted in light of several limitations. First, given the nature of the data, it was not appropriate to conduct statistical analyses so we cannot draw reliable statistical comparisons between different categories of patients. Therefore, our results should be viewed as indicators for future studies. The cross-sectional nature of the survey must also be taken into account when analysing these results as for many participants, there was variation in the time between completing treatment and completing the survey. In addition, this study only presents data on the aspects of life mentioned in the survey and so there may be more benefits of treatment that are not described. Finally, we report results from a survey of PWID who had volunteered and were therefore motivated to participate. We cannot guarantee that the findings are representative of all people who use drugs.

It is also important to highlight the specific strengths of this research. For example, this is one of the first analyses that focus on the self-perceived impact of HCV treatment on mental health and physical wellbeing in people who inject drugs. Many of the outcomes that we report on have not been measured in clinical trials and so these findings add breadth to the literature on patient-level benefits of $\mathrm{HCV}$ treatment. In addition, information from this survey allows us to gain insights on a high-risk and highly stigmatised population that is usually excluded from healthcare programmes and large randomised controlled clinical trials. One of the benefits of this study was that recruitment of participants was driven by patients with the majority recruited through patient associations/organisations. A possible reason for this is that PWID visit community-based organisations more regularly than other healthcare settings [37]. In general, this survey shows that having a variety of different recruitment channels is valuable when recruiting PWID. 


\section{Conclusions}

In this survey analysis, we show that the benefits of $\mathrm{HCV}$ treatment among PWID go beyond clinical outcomes and are linked to improved health and wellbeing. In addition, our results suggest that awareness of effective and welltolerated HCV treatments, as well as understanding the potentially severe consequences of untreated HCV are the main reasons PWID are motivated to access and complete HCV treatment.

\section{Supplementary information}

Supplementary information accompanies this paper at https://doi.org/10. 1186/s12879-020-05426-4.

Additional file 1: Supplementary File 1. Survey Questionnaire Additional file 2: Supplementary Figure 1. Impact of HCV treatment on participants' ability to engage in wider society $(N=124)$.

Supplementary Figure 2. Participants' living situation at the start of HCV treatment and during the survey $(\mathrm{N}=124)$. Supplementary Figure 3. Participants' employment status at the start of HCV treatment and during the survey $(\mathrm{N}=124)$.

\section{Abbreviations}

DAA: Direct-acting antiviral; HCP: Healthcare professional; HCV: Hepatitis C virus; IFN: Interferon; PWID: People who inject drugs

\section{Acknowledgements}

The authors would like to thank all the participants who were involved in this research. The authors also acknowledge Bryony Connor, Elements Communications Ltd. for providing medical writing support and Pamela Walker, Incite for her guidance during this market research project.

\section{Authors' contributions}

MT, TS, DB and ES were involved in the development of the survey questionnaire, data acquisition and analysis, interpretation of the data, and contributed to drafting and reviewing the manuscript with regards to important intellectual content. The authors read and approved the final manuscript.

\section{Funding}

This research was funded by Gilead Sciences Europe Ltd. Gilead Sciences Europe Ltd. were responsible for the study design and the collection and interpretation of data. Medical writing support for manuscript development was funded by Gilead Sciences Europe Ltd.

\section{Availability of data and materials}

The datasets used and/or analysed during the current study are available from the corresponding author on reasonable request.

\section{Ethics approval and consent to participate}

Written informed consent was obtained from all survey participants. Given the nature of this market research project, Clinical Research Ethics Committee and/or Independent Review Board approval was not required, according to the EphMRA code of conduct (Section 1.3). The research team complied with all European laws protecting personal data. To comply with General Data Protection Regulation, data were only collected from the 124 people who completed the survey questionnaire and all responses were anonymised. The research team complied with the ESOMAR, EphMRA, MRS and $\mathrm{BHBIA}$ codes of conduct.

\section{Consent for publication}

Written informed consent was obtained from participants for publication of aggregated, anonymised survey responses.

\section{Competing interests}

Tokunbo Soyemi and Darcy Bowman are employees of Gilead Sciences Europe Ltd. and may own stock or stock options. Marta Torrens has received consultancy fees from AbbVie, Esteve, Gilead Sciences, Lundbeck, Merck Sharp \& Dohme and Servier. The Correlation European Harm Reduction Network receives funding from Gilead Sciences for hepatitis C-related research and activities.

\section{Author details}

${ }^{1}$ Addiction Research Group, Hospital del Mar Medical Research Institute, Barcelona, Spain. ${ }^{2}$ Department of Psychiatry and Forensic Medicine, Universitat Autònoma de Barcelona, Barcelona, Spain. ${ }^{3}$ Medical Affairs, Gilead Sciences Ltd, London, UK. ${ }^{4}$ Public Affairs, Gilead Sciences Ltd, London, UK.

${ }^{5}$ Correlation European Harm Reduction Network, Amsterdam, The Netherlands.

Received: 3 June 2020 Accepted: 16 September 2020

Published online: 24 September 2020

\section{References}

1. World Health Organization. Global hepatitis report; 2017. https://www.who.int/ hepatitis/publications/global-hepatitis-report2017/en. Accessed 28 Aug 2020

2. Thein $\mathrm{H}-\mathrm{H}, \mathrm{Yi} \mathrm{Q}$, Dore GJ, Krahn MD. Estimation of stage-specific fibrosis progression rates in chronic hepatitis $C$ virus infection: a meta-analysis and meta-regression. Hepatology. 2008;48(2):418-31.

3. Chen Q, Ayer T, Bethea $E$, et al. Changes in hepatitis $C$ burden and treatment trends in Europe during the era of direct-acting antivirals: a modelling study. BMJ Open. 2019;9(6):e026726.

4. Olafsson S, Löve TJ, Fridriksdottir RH, et al. Mission possible: In Iceland $95 \%$ of eligible HCV infected patients were initiated on treatment within three years. Results from the Treatment as Prevention for Hepatitis C (TraP HepC) program. AASLD 2019; Poster \#1516.

5. Grebely J, Dore GJ. Treatment of HCV in persons who inject drugs: treatment as prevention. Clin Liver Dis (Hoboken). 2017;9(4):77-80.

6. Grebely J, Larney S, Peacock A, et al. Global, regional, and country-level estimates of hepatitis $C$ infection among people who have recently injected drugs. Addiction. 2019:114(1):150-66.

7. European Monitoring Centre for Drugs and Drug Addiction (EMCDDA). Hepatitis $C$ among drug users in Europe - epidemiology, treatment and prevention; 2016. http://www.emcdda.europa.eu/system/files/publications/2 953/TDXD16002ENN_final_web.pdf. Accessed 28 Aug 2020.

8. Kostić M, Kocić B, Tiodorović B. Stigmatization and discrimination of patients with chronic hepatitis C. Vojnosanit Pregl. 2016;73(12):1116-24.

9. Paquette CE, Syvertsen JL, Pollini RA. Stigma at every turn: health services experiences among people who inject drugs. Int J Drug Policy. 2018:57: 104-10.

10. Stewart BJ, Mikocka-Walus AA, Harley H, Andrews JM. Help-seeking and coping with psychosocial burden of chronic hepatitis C: a qualitative study of patient, hepatologist, and counsellor perspectives. Int J Nurs Stud. 2012; 49(5):560-9.

11. Nardelli S, Riggio O, Rosati D, et al. Hepatitis C virus eradication with directly acting antivirals improves health-related quality of life and psychological symptoms. World J Gastroenterol. 2019;25(48):6928-38.

12. Colledge S, Larney S, Peacock A, et al. Depression, post-traumatic stress disorder, suicidality and self-harm among people who inject drugs: a systematic review and meta-analysis. Drug Alcohol Depend. 2020;207: 107793.

13. Batchelder AW, Peyser D, Nahvi S, Arnsten JH, Litwin AH. "Hepatitis C treatment turned me around:" psychological and behavioural transformation related to hepatitis C treatment. Drug Alcohol Depend. 2015; 153:66-71.

14. Younossi ZM, Stepanova M, Henry L, Nader F, Hunt S. An in-depth analysis of patient-reported outcomes in patients with chronic hepatitis $C$ treated with different anti-viral regimens. Am J Gastroenterol. 2016;111(6):808-16.

15. Sundberg I, Lannergård A, Ramklint M, Cunningham JL. Direct-acting antiviral treatment in real world patients with hepatitis $C$ not associated with psychiatric side effects: a prospective observational study. BMC Psychiatry. 2018;18(1):157.

16. Montague S, Agarwal K, Cannon M. Exploring the emotions of patients undergoing therapy for hepatitis C. Br J Nurs. 2019;28(13):824-8. 
17. Evon DM, Sarkar S, Amador J, et al. Patient-reported symptoms during and after direct-acting antiviral therapies for chronic hepatitis C: the PROP UP study. J Hepatol. 2019;71(3):486-97.

18. Day E, Hellard M, Treloar C, et al. Hepatitis C elimination among people who inject drugs: challenges and recommendations for action within a health systems framework. Liver Int. 2019;39(1):20-30

19. Falade-Nwulia O, Irvin R, Merkow A, et al. Barriers and facilitators of hepatitis C treatment uptake among people who inject drugs enrolled in opioid treatment programs in Baltimore. J Subst Abuse Treat. 2019;100:45-51.

20. Dillon JF, Lazarus JV, Razavi HA. Urgent action to fight hepatitis $C$ in people who inject drugs in Europe. Hepatol Med Policy. 2016;1:2

21. Sperle I, Hedrich D, Palczak K, Singleton N, Zimmermann R. Barriers to HCV testing in drug treatment services for people who inject drugs. INHSU 2018; Poster \#161.

22. Madden A, Hopwood M, Neale J, Treloar C. Beyond interferon side effects: what residual barriers exist to DAA hepatitis $C$ treatment for people who inject drugs? PLoS One. 2018;13:e0207226.

23. Zhang S, Bastian ND, Griffin PM. Cost-effectiveness of sofosbuvir-based treatments for chronic hepatitis C in the US. BMC Gastroenterol. 2015;15:98.

24. Schaefer M, Sarkar R, Diez-Quevedo C. Management of Mental Health Problems Prior to and during treatment of hepatitis $C$ virus infection in patients with drug addiction. Clin Infect Dis. 2013;57(Suppl 2):S111-7.

25. Pawlotsky JM, Feld JJ, Zeuzem S, Hoofnagle JH. From non-a, non-B hepatitis to hepatitis C virus cure. J Hepatol. 2015;62(Suppl 1):S87-99.

26. Chikovani I, Ompad DC, Uchaneishvili M, et al. On the way to hepatitis C elimination in the republic of Georgia -barriers and facilitators for people who inject drugs for engaging in the treatment program: a formative qualitative study. PLoS One. 2019;14:e0216123.

27. Crowley D, Cullen W, Lambert JS, Van Hout MC. Competing priorities and second chances - a qualitative exploration of prisoners' journeys through the hepatitis C continuum of care. PLoS One. 2019;14:e0222186.

28. Rice CM, Saeed M. Hepatitis C: treatment triumphs. Nature. 2014;510(7503): 43-4.

29. Delile J-M, de Ledinghen $V$, Jauffret-Roustide $M$, et al. Hepatitis $C$ virus prevention and care for drug injectors: the French approach. Hepatol Med Policy. 2018:3:7.

30. Kapadia SN, Marks KM. Hepatitis C management simplification from test to cure: a framework for primary care providers. Clin Ther. 2018;40(8):1234-45.

31. Madden A, Hopwood M, Neale J, Treloar C. Beyond cure: patient reported outcomes of hepatitis $C$ treatment among people who inject drugs in Australia. Harm Reduct J. 2018;15(1):42.

32. Roncero C, Ryan P, Littlewood R, et al. Practical steps to improve chronic hepatitis C treatment in people with opioid use disorder. Hepat Med. 2018; $11: 1-11$

33. Helsper CW, Janssen MP, van Essen GA, et al. Effectiveness and costeffectiveness of nationwide campaigns for awareness and case finding of hepatitis $C$ targeted at people who inject drugs and the general population in the Netherlands. Int J Drug Policy. 2017;47:117-25.

34. Myles A. The role of physicians' attitudes and the provision of hepatitis $C$ virus treatment to people who inject drugs. Open Med J. 2016;3(Suppl 1: M6):104-12.

35. Torrens M, Domingo-Salvany A, Alonso J, Castillo C, San L. Methadone and quality of life. Lancet. 1999;353:1101.

36. Préau M, Protopopescu C, Spire B, et al. Health related quality of life among both current and former injection drug users who are HIV-infected. Drug Alcohol Depend. 2007;86:175-82.

37. Biancarelli DL, Biello KB, Childs E, et al. Strategies used by people who inject drugs to avoid stigma in healthcare settings. Drug Alcohol Depend. 2019; 198:80-6.

\section{Publisher's Note}

Springer Nature remains neutral with regard to jurisdictional claims in published maps and institutional affiliations.

Ready to submit your research? Choose BMC and benefit from:

- fast, convenient online submission

- thorough peer review by experienced researchers in your field

- rapid publication on acceptance

- support for research data, including large and complex data types

- gold Open Access which fosters wider collaboration and increased citations

- maximum visibility for your research: over $100 \mathrm{M}$ website views per year

At $\mathrm{BMC}$, research is always in progress.

Learn more biomedcentral.com/submissions 